\title{
Projeto "Comunicação para a cidadania" entre sons e palavras: REFLEXÕES A PARTIR DAS OFICINAS DE JORNAL E RÁDIO ${ }^{1,2}$
}

\section{"Communication to Citizenship" Project between sounds and words: reflections from newspaper and radio workshops Proyecto "Comunicación para la Ciudadanía" entre sonidos y palabras: reflexiones a partir de los talleres de periódicos y de la radio}

\author{
Cláudia Regina Lahni ${ }^{3}$ \\ Laila Cupertino Hallack ${ }^{4}$ \\ Ludyane Chaves Agostini ${ }^{5}$ \\ Raquel Lara Rezende Alves Pinto ${ }^{6}$
}

\begin{abstract}
RESUMO
Este artigo pretende refletir sobre as experiências com educomunicação vivenciadas ao longo das oficinas de jornal impresso e de rádio que integram o corpo de atividades do projeto "Comunicação para a cidadania: tecnologias, identidade e ação comunitária". As reflexões trazem debates voltados para a educomunicação, entendida como leitura crítica dos meios, e cidadania, a partir de suas bases teórica e metodológica, encontradas, em especial, nas obras de Paulo Freire e de Mario Kaplún. Para isso, busca-se visualizar o panorama traçado pelas ações realizadas em um semestre com quinze adolescentes, alunos de escola pública do bairro Santa Cândida da cidade de Juiz de Fora.
\end{abstract}

Palavras-chave: comunicação; educomunicação; cidadania.

\begin{abstract}
This article aims at reflecting on the experiences with educommunication experienced along the printed newspapers and radio workshops that integrate the activities body of the project "Communication to citizenship: technologies, identity and community action". The reflections bring debates on educommunication, as a media critical reading, and on citizenship starting from its theoretical and methodological basis, founded specially in the Paulo Freire's and Mario Kaplún's works. To this end, it is intended to visualize the panorama traced by the actions performed in one semester with fifteen adolescents, students from a public school located in the Santa Candida district in Juiz de Fora city.
\end{abstract}

Keywords: communication; educommunication; citizenship.

1 Trabalho apresentado nos Grupos de Trabalhos, na Divisão Temática de Comunicação, Espaço e Cidadania, do XIV Congresso de Ciências da Comunicação na Região Sudeste.

2 Projeto financiado pela Fundação de Apoio à Pesquisa do Estado de Minas Gerais (Fapemig).

3 Cláudia Regina Lahni é professora do PPGCOM e docente de Comunicação Comunitária da Faculdade de Comunicação (Facom) da Universidade Federal de Juiz de Fora (UFJF). Coordena o projeto "Comunicação para a cidadania: tecnologias", financiado pela Fapemig, Identidade e Ação Comunitária e o Núcleo sobre o Território e a Cidade da Casa de Cultura da UFJF. É mestra e doutora pela ECA-USP.crlahni@yahoo.com.br

4 Graduanda em Comunicação Social pela UFJF. Bolsista BIC-UFJF. lailahallack@yahoo.com.br

${ }^{5}$ Graduanda em Comunicação Social pela UFJF. Bolsista de extensão - UFJF. lca_ufjf@yahoo.com.br

${ }^{6}$ Raquel Lara Rezende é bacharel em Comunicação Social/Jornalismo, pela UFV, e bolsista técnica do Projeto "Comunicação para a cidadania: tecnologias, identidade e ação comunitária”, pela Fapemig. rlrezende@yahoo.com.br 


\section{RESUMEN}

Este artículo pretende reflejar sobre las experiencias con educomunicación vivenciadas a lo largo de los talleres de periódicos impresos y de radio que integran el cuerpo de actividades del proyecto Comunicación para la Ciudadanía: tecnologías, identidad y acción comunitaria. Las reflexiones traen debates acerca de la educomunicación, comprendida como lectura crítica de los medios, y la ciudadanía a partir de sus bases teóricas y metodológicas, encontradas, en especial, en las obras de Paulo Freire y Mario Kaplún. Para eso, se busca visualizar el panorama trazado por las acciones realizadas en un semestre con quince alumnos de escuela pública del bario de Santa Candida de la ciudad de Juiz de Fora.

Palabras clave: comunicación; educomunicación; ciudadanía.

Introdução

O exercício do direito à comunicação tem crescido, a partir de meios alternativos $e$ comunitários e da participação em instâncias decisórias sobre políticas de comunicação, como o Conselho de Comunicação Social, o que contribui para a cidadania, em especial de quem participa diretamente dessas mídias. Isso ocorre, por exemplo, a partir de experiências de comunicação comunitária, como as rádios, jornais, canais de televisão e telecentros comunitários, além da formação de grupos de leitura crítica dos meios. Essas iniciativas fortalecem e são fortalecidas pela reivindicação do direito à comunicação e à informação, garantido pela constituição brasileira. A importância dessas ações se explicita quando pensamos na existência, no Brasil, de um oligopólio que concentra os meios de comunicação de massa nas mãos de poucos - o que se dá tanto em nível nacional como em municípios.

Em diálogo com essa proposta de aproximar a comunicação do cotidiano $e$, principalmente, da esfera de atuação dos indivíduos, o projeto "Comunicação para a cidadania: tecnologias, identidade e ação comunitária" foi pensado. O objetivo é contribuir para a democratização da comunicação e para o exercício da cidadania de jovens da periferia de Juiz de
Fora - município de cerca de 500 mil habitantes, localizado na Zona da Mata de Minas Gerais.

A iniciativa surgiu a partir de discussões entre integrantes do grupo de pesquisa "Comunicação, Identidade e Cidadania" e do mestrado da Faculdade de Comunicação (Facom) da Universidade Federal de Juiz de Fora (UFJF).

Construído com base nas experiências do projeto "Jornal e rádio na UFJF: território de oportunidades", o "Comunicação para a cidadania" se volta para o estudo dos meios de comunicação e busca mudar a realidade dos/as jovens quanto à ampliação do senso crítico e da participação democrática na sociedade, tendo como base metodológica obras de Paulo Freire e Mario Kaplún.

Com o apoio da Fundação de Amparo à Pesquisa do Estado de Minas Gerais (Fapemig), o "Comunicação para a cidadania" também conta com o envolvimento das faculdades de Comunicação e Serviço Social da UFJF, a partir do Polo de Suporte às Políticas de Proteção à Família, Infância e Juventude. Além do grupo de pesquisa e do mestrado, participam do projeto bolsistas da graduação ligados à Pró-reitoria de Extensão (Proex), à Pró-reitoria de Pesquisa (Propesq) e ao Programa de Educação Tutorial (PET) da Facom.

Em atividade desde dezembro de 2007, o projeto trabalhou no primeiro semestre com um grupo de adolescentes vinculados ao "UFJF:

\footnotetext{
7 UFJF: Território de Oportunidades, do qual é parte o projeto Jornal e Rádio, foi um projeto de extensão que atuou entre os anos de 2005 e 2008, trabalhando com jovens da periferia de Juiz de Fora. O Programa reunia docentes e alunos da graduação em Comunicação, Serviço Social (que o coordenava), Letras, Educação Física e outras Unidades da UFJF, que atendiam adolescentes das classes populares, no desenvolvimento de atividades de extensão no Campus.
} 
território de oportunidades" e no segundo semestre com um grupo de adolescentes, alunos/ as da escola municipal Santa Cândida, localizada no bairro Santa Cândida, zona leste de Juiz de Fora.

As reflexões traçadas neste texto se referem às atividades realizadas durante as oficinas de jornal impresso e de rádio, ao longo do segundo semestre, com o grupo de alunos/as da escola Santa Cândida.

As atividades tiveram início em agosto de 2008 e terminaram em fim de novembro do mesmo ano. Nesses quatro meses, os/as adolescentes tiveram seis oficinas semanais de uma hora e meia cada: de jornal e de rádio - coordenadas pela professora Cláudia Lahni -, de TV - coordenada pelas professoras Iluska Coutinho e Christina Musse -, de fotografia - coordenada pelo professor Jorge Felz -, de cultura política coordenada pelo professor Paulo Roberto Figueira Leal - e de novas tecnologias - coordenada pelo professor Bruno Fuser. Além das oficinas de comunicação, a Faculdade de Serviço Social acompanhou o grupo de adolescentes - em encontros quinzenais, nos quais foram trabalhados aspectos socioeducativos e outros temas delineados pelo projeto e sua coordenação.

À medida que os/as adolescentes passam a compreender melhor como a mídia apresenta os fatos à sociedade, são capazes, então, de perceber a comunidade em que vivem com outros olhos. Olhos de quem vivencia a realidade e o cotidiano do bairro, mais capazes de realizar ações comunicativas que explorem os contextos a partir das vivências e com a busca de melhorias sociais.

Essa perspectiva é possível quando estimulada a leitura crítica dos meios, como propõe Mario Kaplún com a educomunicação, termo usado pelo teórico para definir um campo de implementação de políticas de comunicação educativa, de relação entre a educação e a comunicação. Com a preocupação, então, de costurar as ações dentro do projeto guiadas pelo desejo transformador, localizamo-nos sob a luz das obras de Paulo Freire e Mario Kaplún.

\section{Educomunicação como caminho para a cidada-} nia

Sabemos que a educação e a comunicação são ferramentas eficazes para a manutenção da estrutura social que conhecemos. No entanto, também constituem um caminho para a possibilidade de mudança do status quo. Isso porque são processos em que, quando permitido e estimulado, o diálogo é estabelecido, o que promove a construção de um conhecimento em que nos percebemos como sujeitos da construção, $e$ não apenas como coadjuvantes/ouvintes.

Mario Kaplún teve como cerne de seus estudos a educação, colocando a comunicação como ferramenta básica para a cidadania e a inserção social. A partir desse encontro, construiu uma educação comunicativa, acreditando que um diálogo eficaz, no qual o educando é emissor e receptor de mensagens, possibilita uma comunicação horizontalizada, mais rica em trocas $e$ mais próxima de uma construção democrática de conhecimento.

Para o autor, não basta que os setores populares tenham acesso a meios de comunicação para que a participação se torne uma realidade, de cujo processo estes devem ser protagonistas, e não meramente espectadores. A comunicação também deve servir para a mobilização de ações comunitárias e, para isso, aqueles que dela fazem parte não devem se sentir "lejanos y ajenos los mensajes que se le proponen sino que los sienta suyos, propios; que se reconozca en ellos" (KAPLÚN, 1998, p. 80). $\mathrm{O}$ mesmo se verifica no processo educativo.

Como afirma Paulo Freire, as massas populares estão submetidas à "cultura do silêncio", especialmente por meio dos meios de comunicação de massa. Essa realidade opressora, em que as pessoas não podem manifestar suas opiniões e anseios, pode ser quebrada com a 
educação. "Quanto mais as massas populares desvelam a realidade objetiva e desafiadora sobre a qual eles devem incidir sua ação transformadora, tanto mais se inserem nela criticamente" (FREIRE, 1985, p. 42).

Como defensor das relações dialógicas, Freire ressalta a importância da educação para a libertação e a busca por uma sociedade mais igualitária. Ao compreender que o sujeito precisa se sentir parte do mundo a que pertence e não objeto dele, o teórico entende o educando como agente na compreensão, construção e configuração do mundo e da realidade.

Se pensamos que a mídia está presente em grande parte das esferas que preenchem o cotidiano contemporâneo e contribui para a reprodução material da sociedade, entendemos que os conteúdos simbólicos trabalhados por ela configuram essa realidade. De forma que, para ser parte real de sua construção, o educando precisa ter ao seu alcance os meios de não apenas visualizar os processos de produção comunicativa, mas de ter acesso a eles. À medida que o educando se percebe na posição não apenas de espectador mas de agente e ator comunicativo, a sua postura é redesenhada.

Se a sociedade, com suas instâncias e instituições, dita as regras diariamente, em contrapartida o educando pode concordar ou discordar das situações colocadas e, principalmente, traçar outros contornos socioculturais.

A possibilidade de ação transformadora e de inserção na sociedade como sujeito autônomo e consciente constitui o alcance pleno do exercício da cidadania, entendida aqui de forma complexa, que ultrapassa a atuação política, como é localizada pela concepção clássica.

Como Peruzzo salienta, existem algumas noções fundamentais para o entendimento da cidadania:

Primeiro: o cidadão tem direitos e deveres. A participação política, a responsabilidade pelo conjunto da coletividade, o cumprimento das normas de interesse público, são deveres, por exemplo. Segundo: cidadania é histórica. Varia no tempo e no espaço, varia conforme o período histórico e o contexto vivido. Portanto, cabe sempre perguntar quem pode exercer plenamente a cidadania. Terceiro: cidadania é sempre uma conquista do povo. A ampliação dos direitos de cidadania depende da "capacidade política" dos cidadãos, da qualidade participativa desenvolvida. Quarto: as formas de participação decorrem do tipo de sociedade política em que se vive. Quinto: cidadania não se encerra nas suas dimensões de liberdade individual e participação política, mas inclui os direitos sociais e coletivos (PERUZZO, 2002, p. 5).

Dessa forma, percebemos a cidadania como a possibilidade de atuação no coletivo, o que implica a compreensão da sociedade e do papel do indivíduo nesse coletivo, construído polifonicamente.

No processo de compreensão da sociedade, passamos, entre outras coisas, pelo entendimento do papel dos meios de comunicação na configuração vigente. Por isso, a educomunicação se coloca como trabalho imprescindível para a transformação dos indivíduos, na medida em que pauta a urgência de uma educação complexa, dialógica e consoante com a realidade e os instrumentos disponíveis nesse contexto; e a promoção do acesso democrático dos cidadãos à produção e difusão da informação. Criar e desenvolver análise crítica a partir de reflexões e ações, identificar como o mundo é editado pelos meios e possibilitar o uso criativo dos meios de comunicação e uma expressão comunicativa também são ações da educomunicação.

En la medida em que sigamos asumiendo el clásico papel de emisores, de poseedores de la verdad que dictamos 
a verdad a los que no "no saben", en la medida en que sigamos depositando informaciones e ideas ya "digeridas" en la mente de nuestros destinatarios, por libertadores y progressistas que sean los contenidos de nuestros mensajes, continuaremos siendo tributarios de una comunicación autoritaria, vertical, unidirecional (KAPLÚN, 1998, p. 27).

Nesse caminho estão as ações do projeto, com o objetivo de contribuir para o exercício da comunicação, essencial, por sua vez, para a garantia da cidadania. Ao considerar os pensamentos dos dois teóricos trabalhados, o projeto se articula entre a pesquisa e a extensão em comunicação, vislumbrando ações impulsionadas pela reflexão. Traçamos o estímulo à leitura crítica dos/as adolescentes e a elaboração de produtos como jornais e programas de rádio, no que se refere às oficinas de impresso e rádio.

\section{Primeiro contato}

No segundo semestre de 2008, a Escola Municipal Santa Cândida foi escolhida como base territorial. A escola se localiza no bairro Santa Cândida, Zona Leste do município de Juiz de Fora. O bairro apresenta carências no que tange à estruturação social. Não conta com Unidade Básica de Saúde nem escola pública que garanta o ensino médio. Apesar da falta de políticas públicas que garantam o acesso à cultura e à educação, há na comunidade atividades organizadas por seus membros, que buscam, a partir da representação em associações e grupos organizados, formas de cobrar e garantir seus direitos.

As atividades iniciaram com 16 adolescentes, entre 14 e 17 anos, cursando entre a quinta e a nona séries. Chegamos ao final das atividades com sete adolescentes, seis meninas e apenas um menino. O número grande de desistências se deu em função da inserção de muitos deles/as no mercado de trabalho. Para esse grupo não foi possível a disponibilização de bolsas, apenas de vales-transporte e lanche ${ }^{8}$.

Para as seis oficinas, foram estabelecidos temas transversais como o Estatuto da Criança e do Adolescente (ECA), relações de gênero, violência e território. Dentro desses temas, foram abordadas outras questões, como sexualidade, a situação dos/as negros/as e as eleições.

O primeiro encontro com os/as adolescentes se deu com a coordenadora do projeto $e$ também das oficinas de jornal e rádio, professora Cláudia Lahni, e bolsistas envolvidos/as. A preocupação foi de ter contato com os costumes dos/ as adolescentes, principalmente no que tange ao acesso aos produtos midiáticos. Procuramos saber quais programas eram assistidos, que rádios eram ouvidas, se apresentavam hábito de leitura, se sim, que leituras seriam. Com relação à internet, procuramos entender que tipo de relação estabeleciam com a rede.

Nessa reunião apresentamos o objetivo do projeto e fizemos uma dinâmica de apresentação, para conhecermos um pouco da história de cada um. A dinâmica propunha que escrevêssemos no papel aquilo que carregaríamos dentro do nosso "baú" para dar início às atividades do projeto. Os/as adolescentes disseram que levavam "boas expectativas", o "desejo de aprender", "conquista de novas amizades", "a família", "respeito", dentre outros. Em um segundo momento, dividimos toda a turma em duplas para que pudéssemos saber quais eram as preferências dos/as jovens quando o assunto era grande mídia, se conheciam algum trabalho da mídia alternativa, como o da rádio Mega FM

\footnotetext{
8 No primeiro semestre de 2008, o projeto trabalhou com adolescentes do Programa de Extensão UFJF: Território de Oportunidades, coordenado por professoras da Faculdade de Serviço Social. Pelo programa, os/as jovens recebiam uma bolsa mensal de apoio financeiro, além de vales-transporte e outros benefícios; eles/as participavam de atividades de educação física, letramento, línguas, socioeducativo, teatro, hip hop e cinema, além das de comunicação.
} 
de Juiz de Fora, que estava instalada no bairro onde eles/as moram. A maioria deles/as lia jornal raramente e a principal forma de se informar era pela televisão, mais precisamente pelo Jornal Nacional. Muitos/as responderam que se mantêm informados pela internet, quando a acessam em lan houses. Os programas de televisão mais citados e as emissoras foram: Malhação, A Grande Família, novelas da Rede Globo e MTV. Quanto às revistas, elas foram pouco citadas e, quando foram, surgiram principalmente nomes como "Capricho" e "Atrevida". Por outro lado, a rádio Mega FM foi citada, como estação acessada, assim como uma revista ligada a uma empresa. $\mathrm{O}$ telejornal local emitido pela filial da Rede Globo também foi colocado, assim como um programa de entrevista da mesma emissora.

\section{Oficina de jornal impresso}

Na oficina de jornal impresso, os quatro primeiros encontros foram planejados de forma a apresentar aos adolescentes diferentes gêneros e produtos do jornalismo impresso. Para isso, levamos jornais, revistas e fanzines variados e pedimos que cada um/a explorasse aquele produto que chamasse mais a atenção. A escolha foi aleatória e pudemos notar que os/ as jovens escolhiam qualquer um ou aquele que estava mais próximo. Foi dado um tempo para que folheassem o jornal ou revista e optassem pela matéria ou reportagem que mais havia lhes interessado.

Durante o momento reflexivo, os/as jovens não queriam discutir o conteúdo das matérias e nem mesmo dizer o porquê de terem escolhido determinada revista ou jornal. Estavam desatentos/as e não se interessavam pelas discussões que levantamos em sala. Apenas dois deles/ as mostraram interesse e debateram o assunto da matéria que escolheram.

Aspectos do trabalho do jornalista de um jornal impresso diário também foram explorados, no sentido de estabelecermos discussões com relação a pontos importantes para a reflexão do fazer jornalístico e seu papel na sociedade, como imparcialidade e veracidade. Dentro dessas preocupações, abordamos temas como gravidez na adolescência, homossexualidade, relações de gênero, o Estatuto da Criança e do Adolescente (ECA), as eleições (já que estávamos em plena eleição municipal), entre outros.

A participação continuou inconstante e dotada de pouco interesse. Nas semanas seguintes discutimos alguns temas que estavam na mídia, como o 11 de setembro. Muitos/as adolescentes nem sequer tinham ouvido falar do ataque às torres gêmeas norte-americanas. Acreditamos que a pouca idade - havia estudantes com 14 anos - explica o fato. O cronograma proposto pelas bolsistas foi alterado na reunião em que discutimos a política em Juiz de Fora. A falta de atenção e desinformação foi grande. Ao final desse encontro, percebemos que era preciso dar mais liberdade aos adolescentes de escolher aquilo que eles/as queriam discutir e, acima de tudo, problematizar os comentários que surgiam nos encontros.

A decisão de mudar o cronograma das atividades ocorreu em definitivo quando chegamos na sala onde eram realizadas as discussões teóricas e nos deparamos com a seguinte frase no quadro: "Queremos fazer algo nas oficinas de impresso". Diante do exposto, conversamos com a turma para saber quais tipos de mudanças propunham para a oficina de impresso. Ficou claro que queriam produzir e discutir temas mais próximos às suas realidades.

Dessa forma, realizamos uma reunião de pauta em que as adolescentes e o único menino levantaram assuntos sobre os quais gostariam de pesquisar e escrever. Os temas propostos foram: gravidez na adolescência, o uso de lan houses na juventude, músicas (rap) e conflitos existentes entre pais e filhos. Decidiu-se que o trabalho final seria um fanzine, por ser menos formal, dando maior liberdade de expressão aos jovens. Dividimos a turma em duas duplas e um trio. Antes de começarmos a discutir como foi o 
andamento da produção do fanzine, é interessante comentar a visita que ele e elas fizeram juntamente com os/as bolsistas das oficinas de jornal e rádio ao campus da UFJF9 9 .

Nós os/as levamos para conhecer a Faculdade de Comunicação, de Serviço Social e o Instituto de Ciências Humanas (ICH). Na Facom, conheceram o laboratório de rádio, de televisão e de jornal impresso, locais que mais chamaram a atenção. Houve uma adolescente que, ao conhecer o laboratório de TV, manifestou vontade de seguir a carreira de jornalista.

A visita à UFJF suscitou discussões com relação ao acesso à universidade e à educação. Essas questões, na ocasião, também estavam sendo tratadas na oficina de cultura política, o que contribuiu para o aprofundamento das reflexões. Antes da visita, conversamos sobre os desejos de cada um/a com relação à profissão. Procuramos explorar e incentivá-los/as a se questionar acerca de seus sonhos e planos. Todos/ as se projetaram no futuro a partir do desejo de estudar e se firmar em uma profissão que exigia curso superior. Após a visita, a partir das percepções dos/as adolescentes e das entrevistas realizadas por eles/as, escreveram uma matéria sobre como foi a ida à UFJF. $\mathrm{O}$ texto foi afixado no jornal mural da Casa de Cultura.

A produção do fanzine continuou nas próximas semanas. As meninas que atrapalhavam o andamento das exposições teóricas foram as que mais produziram durante a apuração e redação das matérias. O tema escolhido foi "gravidez na adolescência" porque uma delas é prima de uma adolescente de 13 anos que tem um bebê. Foi difícil debater os problemas de uma gravidez inesperada. Elas acreditavam que nada havia mudado na vida da mãe adolescente, que, apesar de não contar com a ajuda do pai da criança, continua frequentando a escola $e$ "sempre quando quer sair à noite deixa a filha com a mãe", como afirmava o tempo todo a prima da menina.
Estimulamos a discussão sobre gravidez na adolescência e a mulher na sociedade em um dos encontros das oficinas de rádio, complementando atividades da oficina de jornal impresso. Convidamos para conversar com os/as jovens uma militante do grupo feminista "Maria Maria - Mulheres em Movimento", Núcleo da Marcha Mundial das Mulheres, de Juiz de Fora, a estudante de Enfermagem Ludmilla Taborda. Este encontro contribuiu para que as meninas, principalmente, revissem a percepção ingênua que tinham com relação à gravidez e à própria sexualidade.

Deixamos que tivessem liberdade no momento da redação das matérias, sem interferir no conteúdo. Assim, como analisa Freire (2007), o educando deve ser tratado como um ser humano que carrega um repertório próprio e como um ser histórico social. Ao final, a correção foi feita juntamente com os/as jovens e foram apontadas possibilidades de mudança em alguns pontos do texto. $\mathrm{O}$ nome escolhido para o fanzine foi " $\mathrm{A}$ cara dos jovens", com um total de seis páginas (tamanho meio-ofício), incluindo um editorial e uma música na última página, "Não é sério", de Charlie Brown Jr. A colagem das matérias foi feita pelas bolsistas mediante as ideias propostas pelos/as participantes da oficina.

O fanzine foi distribuído durante a mostra final do projeto, em que todos os trabalhos dos/as jovens foram apresentados para as famílias, professores/as e a comunidade presente. A alegria de ver os seus próprios nomes nos fanzines impressos estava estampada nos rostos de todos/as.

\footnotetext{
${ }_{9}$ As atividades são realizadas na Casa de Cultura, que não se localiza no campus, que, por sua vez, é distante do bairro onde residem os/as jovens.
} 


\section{Oficinas de rádio}

Nos primeiros encontros da oficina de rádio, conversamos sobre a concessão dos meios de comunicação. Os/as adolescentes mostraram surpresa perante as informações, novas para eles/as. Assim como nas demais oficinas, discutimos sobre o papel dos meios de comunicação, em especial o rádio, pensando nos programas mais ouvidos por eles/as.

$\mathrm{O}$ fato de todos/as terem tido contato, direta ou indiretamente, com a rádio comunitária Mega, que funcionou no bairro Santa Cândida, aproximou os/as adolescentes das discussões sobre a importância das rádios comunitárias e a dificuldade que elas encontram para se manter, entre todas as tentativas de emperramento por parte do governo e da própria mídia comercial. Também a exibição do filme Uma onda no ar, do diretor Helvécio Hatton, suscitou reflexões sobre a contribuição da comunicação alternativa para a comunidade.

Para melhor compreendermos as diferenças de propostas ente as rádios comerciais, comunitárias e educativas, ouvimos estações diversas e conversamos sobre as principais diferenças entre elas, especialmente no que diz respeito a temas, discussões, músicas e a presença e quantidade de propagandas.

Após as discussões, pensamos como seria a rádio desejada pelo grupo. Que assuntos e temas exploraria, se seria mais informativa ou voltada para o entretenimento. Em roda, cada um/a foi apontando características e questões que considerava importantes, e ao final do encontro havíamos construído um projeto de rádio.

$A$ rádio, mais tarde batizada como Rádio do Beco, foi concebida como um meio de comunicação voltado para a realidade da comunidade, preocupado não somente com as problemáticas e deficiências do bairro, mas também com a divulgação e difusão das produções artísticas e culturais dos/as moradores/as. A rádio, numa mescla de informação e entrete- nimento, teria em suas programações músicas prioritariamente não comerciais, que não são divulgadas nas rádios comerciais mais acessadas, o que, no entanto, não exclui a possibilidade de veiculação dessas músicas também. Questões como segurança e violência foram destacadas como temas importantes a ser explorados na Rádio do Beco.

A partir desse imaginário construído, pensamos em dois programas da Rádio do Beco que seriam produzidos. $\mathrm{O}$ primeiro, com base na divulgação do trabalho de artistas da comunidade, voltou-se para o hip hop, manifestação cultural explorada pelos grupos Posse Zumbi dos Palmares (PZP) e Armadilha do Gueto, ambos com sede no bairro Santa Cândida. Os dois grupos trabalham com oficinas de dança e grafite no bairro e, apesar de nem todos/as os/ as adolescentes gostarem do estilo musical, a escolha pelo tema foi consenso, visto que todos/ as estavam de acordo com a importância dos trabalhos desenvolvidos.

O tema do segundo programa foi um pouco mais difícil de ser traçado, entretanto, quando escolhido envolveu os/as adolescentes mais diretamente, rendendo pesquisas profundas com relação ao tema: violência doméstica. Os roteiros dos dois programas foram construídos a partir dos textos e pesquisas de cada um/a, e ao final, juntos/as, adequamos a linguagem escrita para a linguagem radiofônica, que, por sua vez, foi assimilada rapidamente pelos/as jovens. As narrações foram realizadas por eles/as e, apesar de no primeiro momento alguns/as terem apresentado resistência ao microfone, principalmente no primeiro programa, no segundo momento, ao experimentar a narração, empolgaram-se e participaram do segundo programa, tendo assim, todos/as passado pela locução, produção e roteirização do segundo programa.

A escolha das músicas foi o processo mais complexo e que demandou maior negociação. No primeiro programa, após intensa pesquisa sobre as origens e propostas do hip hop, 
percebemos uma grande diferença na produção norte americana atual $e$ anterior e também com relação à produção brasileira. $\mathrm{O}$ hip hop nasceu nos Estados Unidos, como uma cultura urbana marginalizada com cunho social forte. Com o tempo e a apropriação do estilo pela indústria cultural, as músicas de artistas conhecidos hoje internacionalmente, como Akon e Chris Brown - mais citados e ouvidos pelos/as adolescentes -, desviaram-se das preocupações sociais e passaram a explorar temas românticos e mesmo de violência contra a mulher.

O hip hop brasileiro, também acessado pelos/as jovens, principalmente nas obras dos grupos Detentos do Rap e Facção Central, traz em suas letras problematizações, denúncias e contestações da periferia. Com exceção de três adolescentes, a preferência maior era pelas músicas norte-americanas, havendo inclusive por parte das meninas um encanto pelos cantores Akon e Chris Brown. Ao questionarmos o conteúdo das letras das músicas, nenhum/a deles/ as tinha conhecimento nem havia tido interesse em ler a tradução das letras. Fizemos então esse exercício, comparando posteriormente os conteúdos com as músicas dos grupos brasileiros. A diferença se mostrou sensível e, após discussões, todos/as concordaram que a abordagem do hip hop brasileiro se mostrava mais interessante $e$ relevante para a construção social.

$\mathrm{Na}$ produção do segundo programa, um momento importante se deu durante conversa e entrevista com a estudante de enfermagem pela UFJF Ludimila Taborda, integrante do Grupo Feminista Maria Maria, Núcleo Juizforano da Marcha Mundial das Mulheres. Pudemos perceber a existência de muitas dúvidas com relação à sexualidade e saúde da mulher que foram tratadas, além da questão da violência contra a mulher. A conversa despertou nos/as adolescentes um interesse maior pelo tema e pelo programa. Os momentos de locução foram empolgantes e engraçados; os/as jovens tiveram de lidar com o nervosismo, o estímulo e o respeito ao outro. Sentimentos como confiança e amizade se mostraram mais fortes nesses momentos em que todos/as se lançavam a um desafio até então desconhecido.

Ao ouvir os programas editados, foi interessante perceber a reação de cada um/a ao reconhecer sua voz, sua entonação e ao acessar as lembranças daqueles momentos, que ficaram marcados na experimentação e aproximação desse meio de comunicação, o rádio.

\section{Considerações finais}

Na reunião de avaliação, com a presença de professores/as e bolsistas, refletiu-se sobre a dificuldade em trabalhar com adolescentes na faixa etária escolhida. Em atividades anteriores os/as jovens tinham entre 17 e 19 anos e cursavam o ensino médio. Essa diferença de idade acabou chamando a atenção para a necessidade de adequação pedagógica.

Acreditamos que a inconstância no envolvimento e interesse dos/as adolescentes acabou comprometendo o aprofundamento nas discussões e atividades realizadas. No entanto, pudemos perceber mudanças com relação a algumas posturas iniciais, perante os jornais impressos e programas de rádio comerciais. Essas mudanças demonstram que ao longo das atividades foi possível estimular a leitura crítica dos/as jovens e incentivá-los/as a pensar outras formas de comunicação, a partir do momento em que eles/as próprios/as produziram textos dentro de outras linguagens.

A presença dos temas tratados em todas as oficinas com abordagens diferenciadas permitiu a construção de uma rede de informações entre as oficinas, o que contribuiu para a maior assimilação dos conteúdos e discussões.

Mais do que considerar o quanto a educomunicação fez diferença na vida desses e dessas jovens, queremos ressaltar o quanto o 
trabalho do/a profissional desse campo deve ser cuidadoso. A comunicação deve se tornar mais do que um mero instrumento tecnológico, para ser um espaço democrático em que educandos/ as e educadores/as constroem o conhecimento e percebem a realidade a ser transformada. A teoria proposta por Freire e Kaplún deve ser pauta cotidiana destes/as profissionais, para que não cometam o erro da acomodação e façam da educação uma oportunidade para o desenvolvimento social.

\section{REFERÊNCIAS}

BORTOLIERO, Simone. Kaplún, educomunicador. Biografia de um visionário. In: MELO, José Marques et al. (Orgs.). Educomídia: alavanca da cidadania. São Bernardo do Campo: Universidade Metodista de São Paulo, 2006. p. 83-88.

FREIRE, PAULO. Pedagogia da autonomia. São Paulo: Paz e Terra, 2007. 163 p.

. Pedagogia do oprimido. São Paulo: Paz e Terra, 1985. $213 \mathrm{p}$.

. Comunicação ou extensão. Rio de Janeiro: Paz e $\overline{\text { Terra, }}$ 1975. 93 p.
Apesar dos resultados alcançados, observados e demonstrados pelo interesse e postura dos jovens e das jovens, o projeto deve ser revisto constantemente. A cada turma, os esforços devem continuar, demonstrando que a universidade pode ser centro de ações com vistas à inclusão social e à democratização da comunicação.

. Ação cultural para a liberdade e outros escritos. São Paulo: Paz e Terra, 1984. 176 p.

GUARESCHI, Pedrinho; BIZ, Osvaldo. Mídia, educação e cidadania: tudo o que você deve saber sobre mídia. Petrópolis/RJ: Vozes, 2005. 213 p.

LAHNI, Cláudia Regina; PINHEIRO, Marta de Araújo (Orgs.). Sociedade e comunicação: perspectivas contemporâneas. Rio de Janeiro: Mauad X, 2008. 215 p.

PENSAMENTO Comunicacional Latino-Americano PCLA. São Bernardo do Campo: Cátedra Unesco de Comunicação da Umesp/Alaic, v. 4, n. 1, p. 1-10, outdez. 2002.

PERUZZO, Cicilia M. Krohling. Comunicação comunitária e educação para a cidadania.

Texto recebido em $1^{\circ}$ de setembro de 2009 .

Texto aprovado em 6 de outubro de 2009. 